Review

\title{
Sphingomyelin in High-Density Lipoproteins: Structural Role and Biological Function
}

\author{
Roberto Martínez-Beamonte ${ }^{1,2}$, Jose M. Lou-Bonafonte ${ }^{2,3}$, María V. Martínez-Gracia ${ }^{2}$ and \\ Jesús Osada ${ }^{1,2, *}$
}

1 Departamento de Bioquímica y Biología Molecular y Celular, Facultad de Veterinaria, Instituto de Investigación Sanitaria de Aragón-Universidad de Zaragoza, Zaragoza E-50013, Spain;

E-Mail: romartin@unizar.es

2 CIBER de Fisiopatología de la Obesidad y Nutrición, Instituto de Salud Carlos III, Madrid E-28029, Spain; E-Mails: mlou@unizar.es (J.M.L.-B.); mvmartig@unizar.es (M.V.M.-G.)

3 Departamento de Farmacología y Fisiología, Facultad de Ciencias de la Salud y del Deporte, Universidad de Zaragoza, Huesca E-22002, Spain

* Author to whom correspondence should be addressed; E-Mail: josada@unizar.es; Tel.: +34-976-761-644; Fax: +34-976-761-612.

Received: 19 February 2013; in revised form: 20 March 2013 / Accepted: 29 March 2013 / Published: 9 April 2013

\begin{abstract}
High-density lipoprotein (HDL) levels are an inverse risk factor for cardiovascular diseases, and sphingomyelin (SM) is the second most abundant phospholipid component and the major sphingolipid in HDL. Considering the marked presence of SM, the present review has focused on the current knowledge about this phospholipid by addressing its variable distribution among HDL lipoparticles, how they acquire this phospholipid, and the important role that SM plays in regulating their fluidity and cholesterol efflux from different cells. In addition, plasma enzymes involved in HDL metabolism such as lecithin-cholesterol acyltransferase or phospholipid transfer protein are inhibited by HDL SM content. Likewise, HDL SM levels are influenced by dietary maneuvers (source of protein or fat), drugs (statins or diuretics) and modified in diseases such as diabetes, renal failure or Niemann-Pick disease. Furthermore, increased levels of HDL SM have been shown to be an inverse risk factor for coronary heart disease. The complexity of SM species, described using new lipidomic methodologies, and their distribution in different HDL particles under many experimental conditions are promising avenues for further research in the future.
\end{abstract}


Keywords: high-density lipoproteins; phospholipids; sphingomyelin

Abbreviations: APO, apolipoprotein; CHD, coronary heart disease; CM, chylomicrons; HDL, high-density lipoproteins; LCAT, lecithin-cholesterol acyltransferase; LDL, low-density lipoproteins; PC, phosphatidylcholine; SM, sphingomyelin; VLDL, very low-density lipoprotein.

\section{Introduction}

The high-density lipoproteins (HDL) are the smallest and densest of the plasma lipoproteins and are approximately one half protein and one half lipid by weight. The principal protein constituent of HDL is apolipoprotein A1 (APOA1) followed by APOA2; minor protein components are APOA4, APOD, APOE, APOF, APOH, APOJ and APOM. HDL also transport enzymes such as lecithin-cholesterol acyltransferase (LCAT), paraoxonase 1 and 3 and platelet-activating factor acetylhydrolase, and proteins involved in regulating the complement system and protecting tissue from proteolysis [1]. The nascent HDL are secreted by the gut and liver. A current model of nascent or newly secreted HDL proposes that they are formed by a bilayer of phospholipids surrounded by four apolipoprotein molecules. Considering the number of apolipoproteins and the limitation per particle, the range of particles is wide (Table 1) [2]. These particles incorporate cholesteryl esters into their interior, forming their hydrophobic core through the action of LCAT, which transfers a fatty acid moiety from phosphatidylcholine (PC) to cholesterol and forms cholesteryl ester. The incorporation of this compound facilitates the formation of a stable spherical particle, depending on the size, referred to as $\mathrm{HDL}_{2}$ or $\mathrm{HDL}_{3}$. The former are larger than $\mathrm{HDL}_{3}$ and contain more lipid-rich particles, whereas $\mathrm{HDL}_{3}$ are relatively protein-rich, lipid-poor and dense [3]. Another source of nascent HDL is hydrolysis of the triglyceride-rich lipoprotein particles-chylomicrons and very-low-density lipoproteins which results in the formation of $\mathrm{HDL}_{2}$. Different states of maturation also result in a wide range of HDL sizes - 26, according to nuclear magnetic resonance technology [4] (Table 1).

Table 1. HDL subspecies depending on analytical preparation.

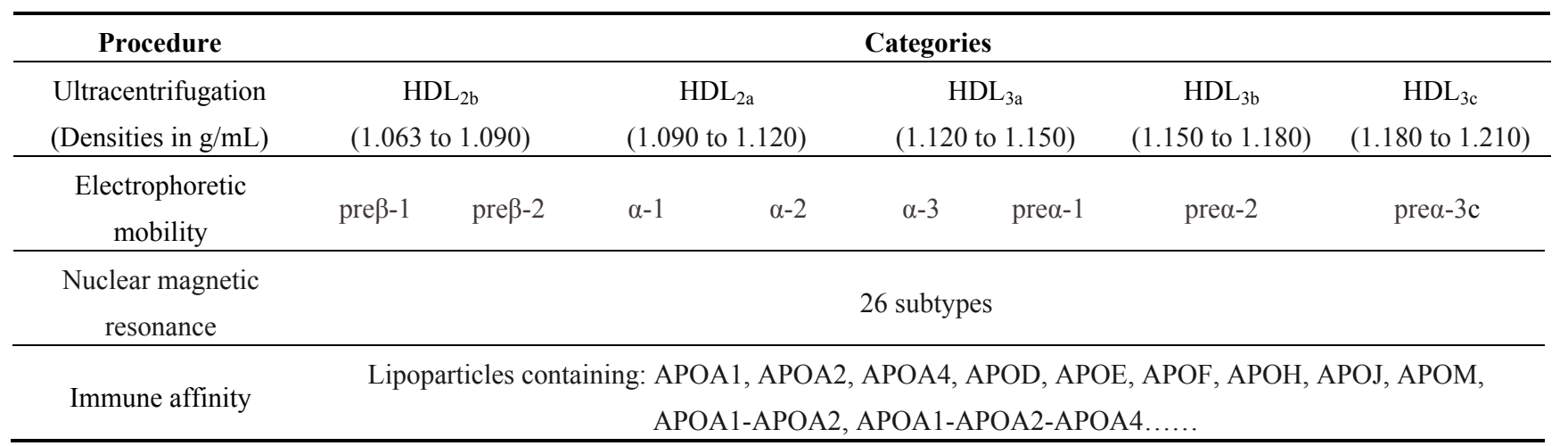

Results from four common analytical methods revealing the heterogeneity of HDL lipoparticles, and reflected categories from one method do not necessarily correspond to another. Adapted from [4,5].

A low level of high-density lipoprotein cholesterol (HDL-C) is a powerful risk factor for cardiovascular disease. The exact role of HDL in atheroprotection is not yet well understood, in part 
due to the existence of different lipoparticles (Table 1) that vary in size, composition and function [2]. Furthermore, oxidative modification of these particles at the lipid [6,7] or protein level [8] increases the heterogeneity and renders them dysfunctional and pro-atherosclerotic [9]. Isolation and deep characterization of these lipoparticles will provide crucial information for understanding the function of HDL in health and disease.

The major lipid constituents of HDL are phospholipids-PC, SM and lysoPC, followed by cholesterol and cholesteryl ester. HDL also carries other lipids including sterols, triglycerides, fat-soluble vitamins, ceramide, sphingosine-1-phosphate and dihydrosphingosine-1-phosphate [10] (Recent reviews addressing their function can be found in $[11,12]$ ). New analytical technologies to tackle the HDL lipidome are characterizing hundreds of lipid compounds based on the fatty acids present in these compounds $[10,12,13]$ and their physiological and pathological variations await further research.

Sphingomyelin or $\mathrm{N}$-acyl-sphing-4-enine-1-phosphocholine encompasses a wide range of compounds depending on the length and unsaturation of the acyl residue and the length of the sphingoid bases (Figure 1), the former being more relevant in terms of structural changes. Despite the fact that SM is the second most abundant phospholipid and the main sphingolipid in HDL [10], its physiological function is unclear. To make advancements in the field, the present review has been carried out according to the criteria shown in Figure 2.

Figure 1. Different molecules of sphingomyelin according to the length and unsaturation of the acyl residue and sphingoid. A, fatty acid compositions of sphingomyelin species (yellow box) and A and B, long-chain base compositions of sphingomyelins (blue box). Note that the major difference among SM molecules is length and saturation of fatty acids. (http://www.lipidmaps.org/data/structure/LMSDSearch.php?Mode=ProcessClassSearch\&L $\mathrm{MID}=\mathrm{LMSP} 0301 \& \mathrm{~s}=$ sphingomyelin $)$.

A

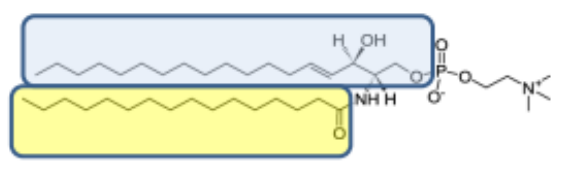

$\mathrm{N}$-(hexadecanoyl)-sphing-4-enine-1-phosphocholine or sphingomyelin 16:0

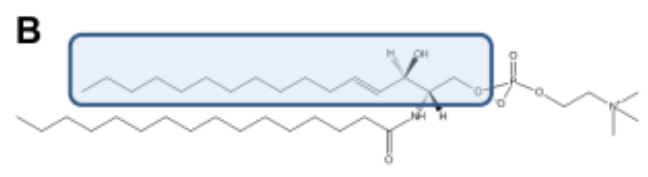

$\mathrm{N}$-(hexadecanoyl)-hexadecasphing-4-enine1-phosphocholine or SM (d16:1/16:0)

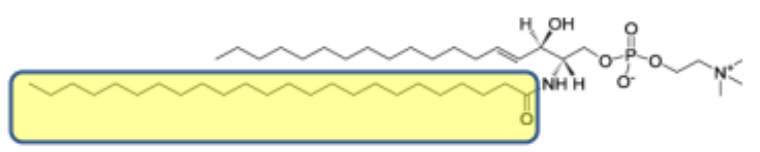

$\mathrm{N}$-(tetracosanoyl)-sphing-4-enine-1-phosphocholine or sphingomyelin 24:0

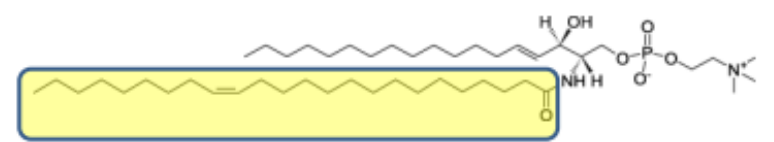

$\mathrm{N}$-(15Z-tetracosenoyl)-sphing-4-enine-1-phosphocholine or sphingomyelin $24: 1$ 
Figure 2. Flow chart displaying the stages used to select the references considered. The present report has adhered to systematic review guidelines [14]. A search in Pubmed (http://www.ncbi.nlm.nih.gov/pubmed/) using the keywords "high-density lipoprotein and sphingomyelin," "sphingomyelin and diet," "sphingomyelin and drugs," "plasma and sphingomyelin," identified 3,389 hits from November 1945 to March 2013. Documents that failed to meet the criteria shown were discarded. Thus, this review covers the works related to sphingomyelin and HDL in 181 papers. EndNote X1 (Bld 2566, Thomson Reuters: New York, NY, USA, 2007).

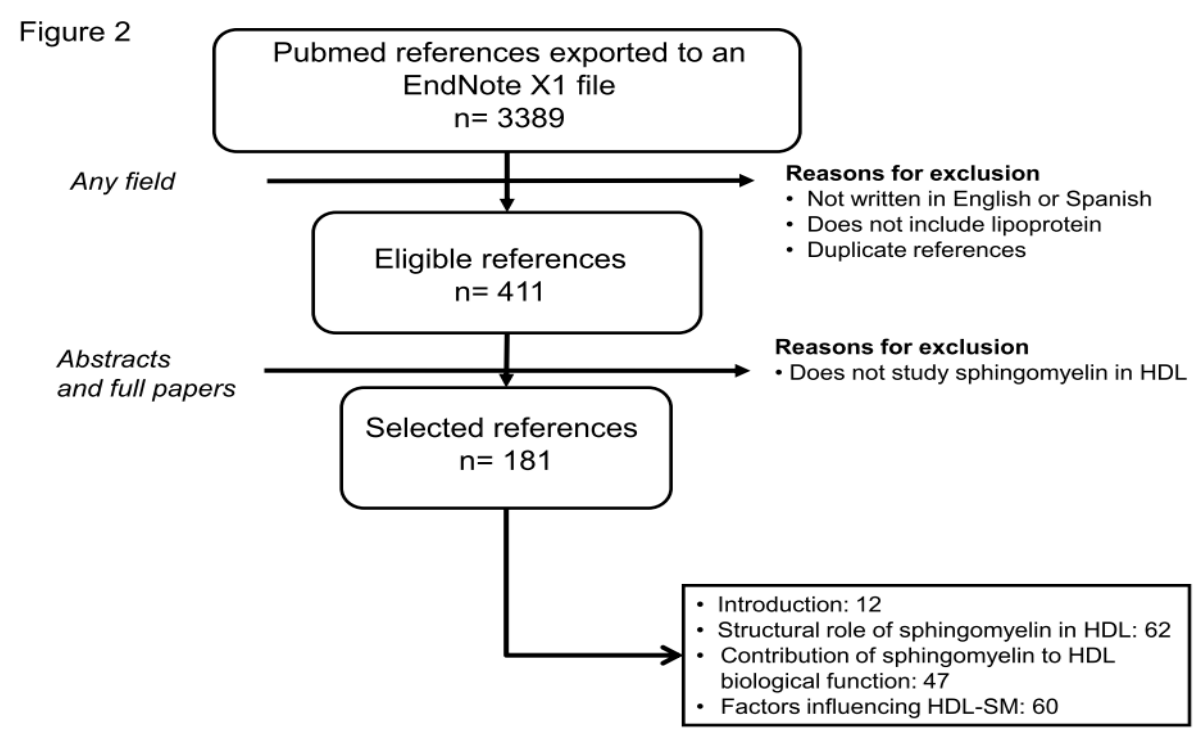

\section{Structural Role of Sphingomyelin in HDL}

\subsection{Distribution into HDL Subclasses}

As previously mentioned, SM is the second most abundant phospholipid in HDL. However, there is a wide heterogeneity among HDL particles. Indeed, SM decreased in abundance in parallel with the progressive increase in HDL density from $\mathrm{HDL}_{2}(19 \%)$ to $\mathrm{HDL}_{3}(6.5 \%)$ [5,10,15-17]. Other authors have found higher proportions of SM for the latter particle. Davidson et al. reported that the $\mathrm{HDL}_{3}$ phospholipid fraction in plasma from five normolipidemic subjects contained 12\% SM [18]. This discrepancy could be explained by the inhibition of phospholipid transfer protein or hepatic lipase during the isolation procedure, as referred to by Marques-Vidal et al. [19], or the moment of extraction, since fasting is an important factor [10]. The distribution of phospholipids in HDL is similar in other species, although SM content may vary widely from $4.5 \%$ in mouse to $19.7 \%$ in American armadillo [20]. Intermediate values are observed in baboon (5.9\%) [21], dog (8.7\%) and cat $(10 \%)$ [20]. In all of them, SM represents the second most abundant phospholipid and this phylogenetic conservation may suggest an important role.

Heterogeneity among subclasses of HDL with respect to content of SM has also been observed using immunoaffinity chromatography. In this regard, $\mathrm{HDL}_{3}$ containing APOD were found to be particularly rich in this phospholipid [22], as were gamma-LpE, an HDL containing APOE [23], and those containing APOA4 or APOA1/APOA2/APOA4 [24]. However, using filtration through a polyacrylamide gel under the effect of an electric field, the seven HDL subclasses observed, with 
respective molecular masses of 42-50,71, 103, 124, 150, 182 and $219 \mathrm{kDa}$, showed a similar composition [25]. The source of HDL also generates variation. In fact, lymph HDL lipids had a significantly higher SM content expressed in terms of its relationship to PC (SM/PC ratio) [26]. Lymph HDL apoprotein composition differs from that of plasma, with an increase in APOE and APOA4 content relative to APOA1. These discoidal HDL particles could be products of an initial stage of reverse cholesterol transport [27].

\subsection{Source of Sphingomyelin}

The SM for lipoprotein is formed through several reactions: the first one, catalyzed by serine-palmitoyl transferase, forms dihydrosphingosine from palmitic acid and serine. Dihydrosphingosine is converted into ceramide in three sequential steps catalyzed by dihydrosphingosine reductase, dihydroceramide synthase and dihydroceramide reductase. Sphingomyelin synthase (SMS) catalyzes the transfer of phosphocholine moiety from PC to ceramide, resulting in SM and diacylglycerol [28]. Two enzymes, SMS1 located at the Golgi and SMS2 at the plasma membrane, have been characterized [29], and SM can be added to APOA1 at both locations [30]. In the plasma membrane, SMS2 is located in membrane domains rich in SM and cholesterol referred to as rafts [29,31]. Besides the original phospholipids contained in nascent HDL, the efflux of these lipids from cells contributes to the phospholipid content of HDL. In this regard, $\mathrm{HDL}_{3}$ promoted the efflux of phospholipids from human skin fibroblasts in a concentration-dependent manner and the major phospholipids released were PC, SM, lysoPC and phosphatidylethanolamine [32]. Lipid-free APOA1, interacting with specific regions of plasma membrane fibroblasts, is able to acquire phospholipids [33]. Based on the similarity of lipid composition of nascent HDL and lipid rafts, it has been proposed that these raft-like regions may provide the lipids to HDL [34]. Using fibroblasts from Niemann-Pick type C patients, APOA1-mediated efflux of PC and SM was reduced, suggesting that the cholesterol trafficking defect observed in this disease influences HDL characteristics [35]. APOA1 binding to artery-derived human smooth muscle cells depleted them of PC and SM. In contrast, rat smooth muscle cells or human vein-derived cells released only a small fraction of these phospholipids to APOA1-containing medium. In Raw 264.7 macrophages and CHOK1 cells, only PC (but not SM) was found to be effluxed from both cell lines [36]. The marked difference between these cells may reflect cell- and species-specific mechanisms of phospholipid efflux [37,38]. Similar differences among species were found for phospholipid transfer protein regarding selective transfer of SM between membrane surfaces [39]. It has also been noted that the use of APOA1 or $\mathrm{HDL}_{3}$ makes a difference with respect to the phospholipid species effluxed from fibroblasts and macrophages. In this regard, medium chain SM species containing 14:0 or 16:1 were translocated preferentially to APOA1 and not to $\mathrm{HDL}_{3}[40]$.

\subsection{Interaction of SM with Apolipoproteins}

Several experiments have been undertaken to understand this aspect. SM accelerated the formation of reconstituted HDL by APOA1 when added to unilamellar vesicles comprised of PC [41]. In addition, it modified HDL particle size and stability and the negative surface charge of APOA1 [42]. Treatment of the $\mathrm{HDL}_{3}$ with sphingomyelinase induced a progressive fluidization which suggests that 
SM together with PC modulates the fluidity and order of the surface of $\mathrm{HDL}_{3}[43,44]$ and the SM/PC ratio is considered to be an index of rigidity. Moreover, complete degradation of SM resulted in an increase in the rate of $\mathrm{HDL}_{3}$ cholesterol oxidation [45], suggesting an increased exposure of the compound or an antioxidant action of SM, as reported in other lipoproteins [46].

In HDL, SM was located in a hydrophilic environment and its interaction with apolipoproteins was not particularly relevant in the formation of these plasma complexes (Figure 3) [47,48]. In fact, it was proposed that the stability of the vesicle lipoprotein was related to the cholesterol/phospholipid ratio in these particles $[49,50]$. Compared with SM liposomes, the polar head groups of these lipids in the lipoprotein particles displayed a considerably higher mobility [51]. Not surprisingly, the molecular interactions and spatial arrangements of phospholipids and apolipoproteins of human HDL revealed a spatial relationship between the hydrophobic side chains of the lipid and polypeptide chains in the lipoprotein complex [52]. The mechanisms of interaction between APOA1 and either bovine brain SM or PC are similar, but the nature of the protein-lipid interactions with SM allows the production of larger and more stable complexes than those observed with PC [53]. While a more extensive interaction was described for APOA1, SM interacts with the $\mathrm{COOH}-$ but not the $\mathrm{NH}_{2}$-terminal region of APOA2 [54]. For this reason, APOA1 recruited significantly more phospholipid and cholesterol than APOA2 and showed a special preference for SM [55-57]. Using labeled SM, it was possible to demonstrate a differential interaction with the apoprotein tryptophans, as well as a non-random distribution at the surface of the particles [58]. In APOA1 Seattle (deletion of amino acids Glu146 to Arg160), nascent HDL showed a significant increase in SM compared to wild type nascent HDL [59], suggesting a better availability of interacting regions.

Figure 3. Location of SM and other surface components of HDL. Phosphate choline groups of sphingomyelin on the surface are depicted close to cholesterol molecules in a HDL lipoparticle.
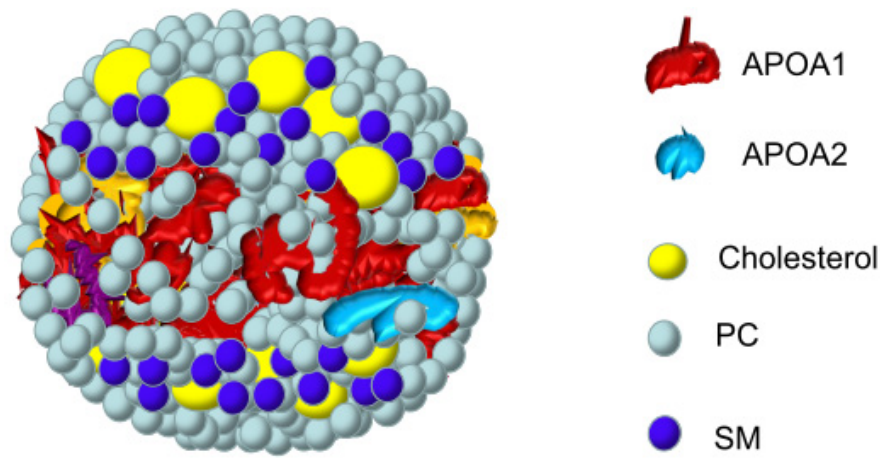

\subsection{Different SM Species}

The existence of different SM molecules has been mentioned earlier (Figure 1). In this respect, a peculiarity of SM from HDL in normolipemic subjects is that their molecular weights are higher than those of other lipoproteins due to the longer chain length of the fatty acids in the ceramide molecules. Indeed, SM 24:1 was the second most abundant species both in $\mathrm{HDL}_{2}$ and $\mathrm{HDL}_{3}$ [10], but its plasma levels decreased in response to diabetes induction and high-fat diets [60], and SM 23:3 acted as a discriminator among subjects with different HDL levels [61]. This has been interpreted as a lateral 
phase separation of the short and long-chain SM during the shedding of the excess VLDL or chylomicron surface material and a subsequent preferential transformation of the long-chain species into HDL [62-65]. Using liquid chromatography-mass spectrometry, SM 16:0 has been found to be the predominant species in human HDL $[10,66]$, although it is present in a much smaller amount than in LDL [67]. Sphingomyelin 16:0 was found to be more elevated in $\mathrm{HDL}_{2}$ than $\mathrm{HDL}_{3}$ [10]. This differential composition seems to develop in adults since, in suckling rats, the fatty acid composition of SM was relatively constant in all lipoprotein fractions [68].

\subsection{Metabolic Fate of HDL Sphingomyelin}

The effects of the removal of SM from HDL have been examined in several tissues. While the rat brain hardly utilizes very long-chain fatty acids from HDL SM, even during the myelination period [69], many other tissues may take up intact SM from HDL and hydrolyze it [70]. Treatment of HDL with hepatic lipase did not affect the delivery of SM [71]. In contrast, pretreating platelets with elastase dose-dependently inhibited uptake of SM from HDL. Therefore, the uptake of this phospholipid appears to require the presence of specialized platelet membrane proteins [72]. These findings indicate a selective mechanism for removal of SM from tissue that needs to be characterized molecularly.

In vivo transfer of SM from HDL to VLDL was also observed [73,74]. The same occurred between LDL and HDL, and inhibition of plasma LCAT reduced the exchange of SM [75].

\section{Contribution of Sphingomyelin to the Biological Function of HDL}

The following sections cover the main actions of HDL in which SM has been shown to participate.

\subsection{Reverse Cholesterol Transport}

The inverse association between HDL cholesterol and coronary heart disease has been attributed to reverse cholesterol transport, this being the main function of HDL, with cellular efflux as the first step in the process. The proportion of HDL-SM could be used to predict the capacity of serum to accept cellular cholesterol since it was positively correlated with its fractional efflux [76]. Moreover, HDL-SM had the strongest inverse association with the presence of coronary heart disease among all HDL-related parameters upon multivariate analysis of data from women with angiographically assessed disease. In fact, it was the only HDL-related parameter that had a significant and independent correlation with the number of coronary stenoses [77,78]. Early experiments of Stein et al. demonstrated that the removal of cholesterol could be enhanced by addition of sonicated suspensions of PC or SM to human high-density apolipoproteins [79-82]. Using reconstituted discoidal HDL particles prepared with APOA1, it was shown that increasing the content of SM, up to $20 \mathrm{~mol} / \mathrm{particle}$, was associated with significantly increased abilities of the HDL to promote cholesterol efflux from non-cholesterol-loaded human skin fibroblasts [83], from erythrocyte ghost membranes [84] or from Fu5AH cells [85]. Sphingomyelin promoted similar cholesterol efflux in control, familial HDL deficiency or Tangier disease fibroblasts [86]. It was concluded that discoidal, phospholipid-rich recombinant lipoproteins could effectively take up substantial amounts of cholesterol from 
physiological membranes, provided that the phospholipids utilized to form micellar complexes retained their structural integrity during the incubation. Reconstituted HDL with sphingomyelin and APOA1 Milano promoted the greatest cholesterol efflux in each cell type (CHO cells, J774 macrophages, and BHK cells) and this was enhanced by increased expression of ATP-binding cassette sub-family G member 1 (ABCG1) [28,87]. This transporter has been shown to preferentially secrete SM $[88,89]$, in contrast to ABCA1 [90], and this phospholipid stimulated the ATPase activity of ABCG1 and increased the affinity for cholesterol, suggesting different binding sites for cholesterol and SM, which may be synergistically coupled [91]. On the other hand, the ABCG1-mediated efflux of cholesterol and SM is dependent on the cellular SM level and distribution of cholesterol in the plasma membrane [92], as reflected in Figure 4. Furthermore, HDL-mediated cholesterol efflux was partially inhibited by sphingomyelinase treatment [93]. The situation may be more complex since high SM content decreased uptake in reconstituted HDL-containing linolenic acid, whereas it increased efflux for reconstituted HDL-containing oleic or linoleic acid [94]. Other authors have confirmed these findings [95] and suggest that HDL removes cholesterol depending on HDL fatty acids. However, increasing membrane SM content increased the time required for cholesterol exchange in both the erythrocyte plasma membrane and in simple mixed SM/PC bilayers [96]. When Slotte et al. used $\mathrm{HDL}_{3}$ as a physiological acceptor for cholesterol, treatment of cells with sphingomyelinase induced a dramatically increased esterification of plasma-membrane-derived $\left[{ }^{3} \mathrm{H}\right]$-cholesterol [97]. An increase in the level of $\left[{ }^{3} \mathrm{H}\right]$-cholesterol efflux to HDL was also observed after degradation of plasma membrane SM with exogenous sphingomyelinase in fibroblast plasma membranes [98,99]. Under these conditions, cellular release of cholesterol may be enhanced by a ceramide-signaling cascade after sphingomyelinase treatment [100] or SM depletion [101]. These results show the importance of SM in reverse cholesterol transport and that cholesterol molecules interacting with SM in the plasma membrane domain appear to be primarily used for HDL assembly when they interact with cells. Thus, due to its specific interactions with cholesterol, SM may represent an important factor accounting for the inverse association between HDL cholesterol and coronary heart disease.

Figure 4. Current model of SM on cholesterol efflux. SM both in HDL and cell membrane regulates ATP binding cassette proteins implicated in reverse cholesterol transport. Cellular SM has been described as a stimulant of SM and cholesterol efflux through ABCG1, ATP-binding cassette transporter G1 [92]. On the other hand, cell membrane SM inhibits ABCA1, ATP-binding cassette transporter A1 activity [102], while SM present in HDL stimulates activity of this transporter [103].

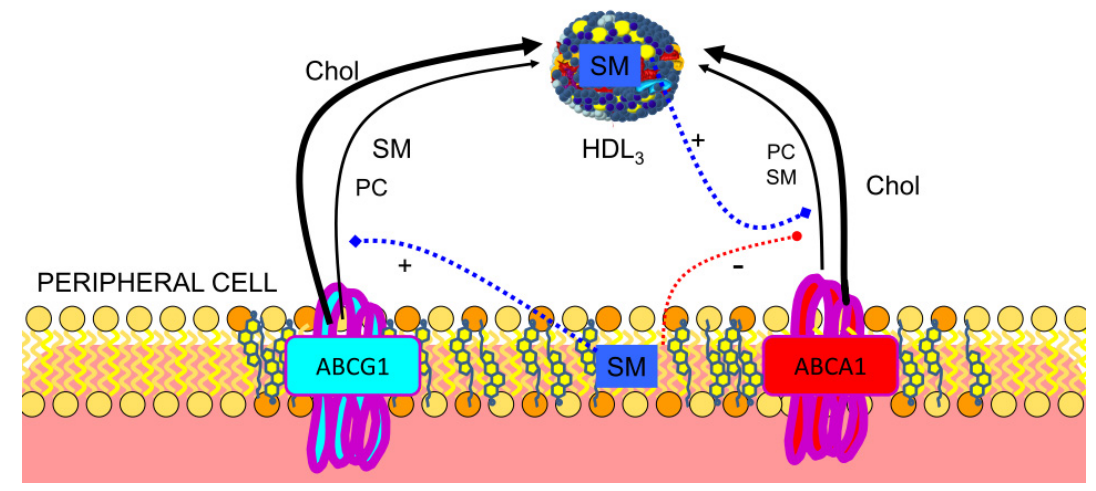




\subsection{Regulation of $A B C A 1$}

ATP-binding cassette protein A1 (ABCA1) plays a major role in cholesterol homeostasis and HDL metabolism, specifically its activity is critical for HDL biogenesis. APOA1 binds to ABCA1 and this translocates phospholipids and cholesterol directly or indirectly to form pre- $\beta$ HDL. Downregulation of ABCA1 expression by interferon-gamma in murine peritoneal macrophages resulted in reduced PC and SM efflux to APOA1 [104]. It has been suggested that the ATPase activity of ABCA1 is stimulated preferentially by PC and SM [103] and that ABCA1 stability is controlled by apolipoprotein-mediated signaling requiring SM since digestion of this lipid increased ABCA1 stability [102]. Nevertheless, Tamehiro et al. demonstrated that serine palmitoyltransferase enzyme subunit 1 negatively regulated ABCA1 function by a physical interaction and that a reduced level of sphingomyelin synthesis was not involved [105].

\subsection{Regulation of Plasma Enzymes}

The activity of several enzymes (phospholipid transfer protein group, group $\mathrm{V}$ secretory phospholipase $\mathrm{A}_{2}$, lipoprotein lipase and LCAT) has been found to be modulated by SM, as reflected in Figure 5. Early experiments showed that SM played a role in phospholipid transfer from liposomes to human HDL. In fact, an increase in the amount of bovine brain SM in egg PC liposomes decreased phospholipid leakage from said liposomes in the presence of serum. Sphingomyelin itself was not readily exchanged with HDL, possibly due to intermolecular hydrogen bonding between the sphingosine backbones of the SM molecule [106]. Sweeney and Jonas later proved that the activity was attributable to human plasma phospholipid transfer protein and that this was inhibited by SM, as well [107].

Figure 5. Role of HDL-SM in modulating enzymes of HDL metabolism. SM and cholesterol have been described as inhibitors of PLTP, phospholipid transfer protein. SM has been also described as inhibitor of GVSPLA 2 , group V secretory phospholipase $A_{2}$, LPL, lipoprotein lipase and LCAT enzymes [42,107-111].

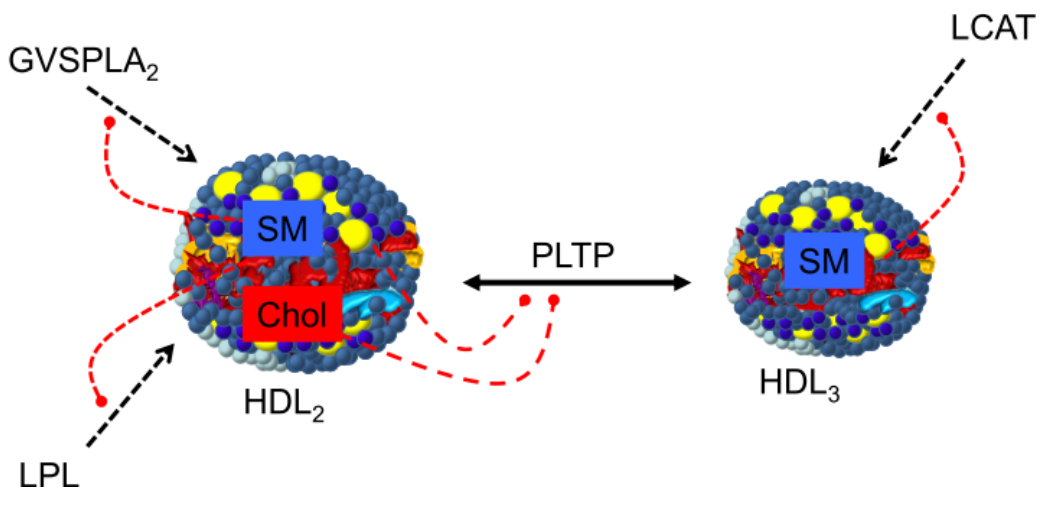

Group V secretory phospholipase $\mathrm{A}_{2}$ activity was also inhibited by SM [112] and, in addition, SM modifies selectivity for arachidonate [108,113]. Likewise, increasing the amount of SM (up to $22 \mathrm{~mol} \%$ ) in reconstituted HDL-containing PC, cholesterol and APOA1 was found to inhibit lipoprotein lipase [114]. 
Using reconstituted HDL, it was found that LCAT was inhibited by up to $90 \%$ in the presence of $\mathrm{SM}$, an effect that was less pronounced when accumulation of cholesteryl ester product directly inhibited LCAT [115], and reversed by treatment with bacterial sphingomyelinase. Kinetic studies showed that LCAT binds more effectively to vesicles with SM, and that the latter competes with the substrate PC $[42,43,109,116]$. A relationship between plasma SM content and LCAT activity has been shown in several animal models, reinforcing in vitro data and pointing to $\mathrm{SM}$ as a physiological modulator of LCAT activity [110,117].

\subsection{SR-BI in Lipid Transfer to the Cells}

Scavenger receptor BI (SR-BI) is the first molecularly defined receptor for HDL. It can mediate the selective uptake of cholesteryl ester into cells with no or partial SM uptake. This requires integrity of membrane rafts and occurs via a retroendocytic pathway in HepG2 cells [118,119]. The interaction of APOA1 with SR-BI not only prevents fusion of the lipid donor with the plasma membrane, but also allows the optimal selective lipid uptake [120]. The role of HDL phospholipid in SR-BI-mediated free cholesterol flux was examined by manipulating $\mathrm{HDL}_{3} \mathrm{PC}$ and $\mathrm{SM}$ content, and it was found that enrichment of HDL with either of these phospholipids enhanced the net efflux of cholesterol from SR-BI-expressing COS-7 cells, but by two different mechanisms. Phosphatidylcholine enrichment of HDL increased efflux, whereas SM enrichment decreased influx of HDL cholesterol [121]. Subbaiah et al. confirmed that incorporation of SM into reconstituted HDL strongly inhibited the uptake of cholesterol esters and that this inhibition was completely reversed by treatment of HDL with sphingomyelinase [31]. A similar phenomenon was observed using intestinal brush border membrane vesicles and Caco-2 cells in a process mediated by SR-BI and CD36 [122]. Overall, these data indicate that SR-BI-mediated free cholesterol flux is dependent on the structure of the donor lipoprotein [123] and that SM is playing an important role, as reflected in Figure 6.

Figure 6. Influence of SM in delivering cholesterol to cells through the SR-BI receptor. SR-BI mediates cholesterol ester influx by the cells but also bidirectional flux of unesterified cholesterol and phospholipids between HDL and cells. Both cell membrane and HDL SM inhibit SR-BI transport activity, while HDL PC stimulates its transport activity [31,121,122].

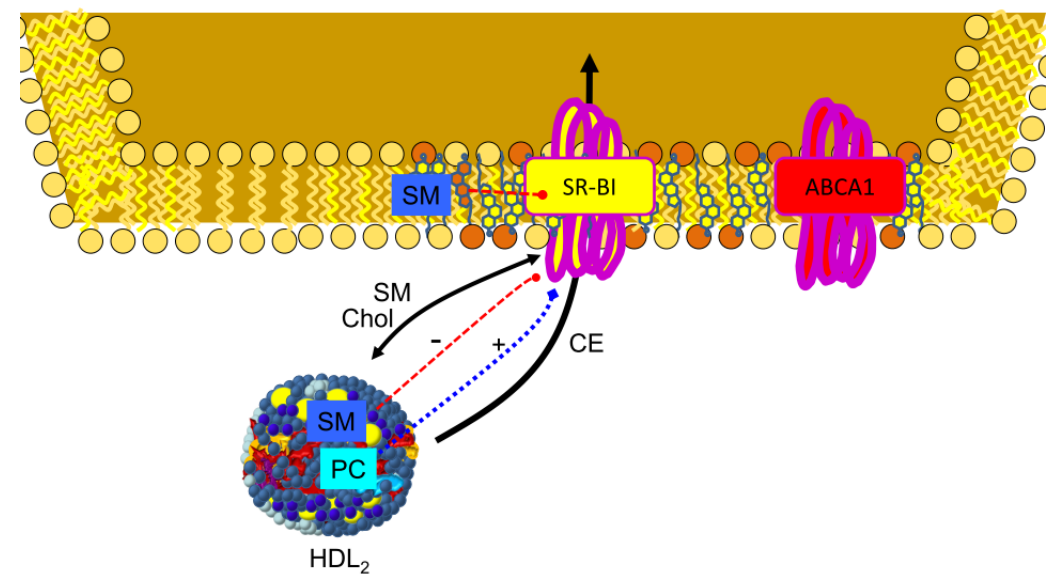




\section{Factors Influencing HDL-SM}

\subsection{Aging and Sex}

Aging has been proposed to attenuate cholesterol efflux (see review [124]). Among many changes, the composition and structure of HDL revealed an increase in the SM/PC ratio and in the phospholipid membrane fluidity in HDL in the elderly compared with HDL in younger individuals, as well as an alteration in the APOA1 structure and charge. Interestingly, reduction in the HDL-mediated cholesterol efflux capacity with aging was more significant with $\mathrm{HDL}_{3}$ than $\mathrm{HDL}_{2}$. ABCA1-mediated cholesterol efflux was the more affected pathway in terms of cholesterol-removing capacity [125].

The only manuscript studying sex differences showed lower HDL SM values in men than in women. HDL SM values were independent of age in both sexes, with the exception that HDL SM concentrations were lower in men aged 55 years or over [126].

\subsection{Lifestyle}

More prolific is the aspect of dietary influence in terms of species and food components. In $L d l r$-deficient mice, a diet rich in saturated fats and cholesterol increased HDL-SM, expressed either as nanomole per milliliter of serum or nanomole per milligram of protein [127]. In rats, the source of polysaccharide and protein and the nature of fat influence HDL SM. For example, pectin (20 g/100 g) increased SM content in the $\mathrm{HDL}_{2}$ fraction in rats [128], while casein feeding (35 g/100 g) lowered $\mathrm{HDL}_{2} \mathrm{SM}$ concentrations when compared to soybean protein-fed rats. Plasma transfer of SM from $\mathrm{HDL}_{2}$ to VLDL could be involved [129]. Dietary olive oil $(180 \mathrm{~g} / \mathrm{kg})$ reduced HDL SM content compared to coconut fat in rats. The lower value may be explained by a simultaneous elevation of SM catabolism and reduction in its synthesis [130]. However, a postprandial elevation of HDL SM, accompanied by intestinal expression of SM synthase 1 mRNA, was observed in rats receiving a bolus of $5 \mathrm{~mL}$ of extra virgin olive oil [131]. Likewise, conflicting results have been observed regarding sphingolipid-rich diets: while HDL-lipids were not significantly altered in LDL receptor gene knockout mice [132], other authors have described changes [133]. More studies addressing different experimental animals and regimes are required to clarify the issue.

In humans, consumption of a diet rich in n-3 polyunsaturated fatty acids seemed to increase SM in $\mathrm{HDL}_{2 \mathrm{~b}}$ and $\mathrm{HDL}_{3}$, and was associated with higher $\mathrm{HDL}$ cholesterol levels in plasma [134]. Sphingomyelin composition was not modified by dietary fat in healthy young male participants [135], nor were any changes observed in subjects consuming various isocaloric diets, each containing 30\% of the calories as fat [136]. In the latter study, $15.6 \%$ of the total calories were provided successively by olive oil, soybean oil, corn oil or milk fats. In a seven-week double-blinded, randomized, controlled, parallel group study with healthy subjects, an increase in SM of long-chain polyunsaturated fatty acids was observed in subjects receiving capsules containing $8 \mathrm{~g} / \mathrm{d}$ of fish oil (1.6 g/d EPA + DHA), compared to those consuming $8 \mathrm{~g} / \mathrm{d}$ of high oleic sunflower oil [137]. Minor dietary components may also influence the results since the consumption of high-polyphenol chocolate increased HDL SM [138]. Plasma SM 16:1 was found to be associated with decreased risk of diabetes [139], and plasma levels of SM 24:1 decreased in response to diabetes induction and high-fat diets [60]. Whether these changes also take place in HDL SM needs to be explored. 
Few studies have addressed exercise; regarding this aspect, a single exposure to a $100-\mathrm{km}$ run did not modify HDL SM [140].

Ethanol consumption in rats was found to have decreased HDL SM, with a concomitant decrease in cholesterol efflux compared to that of controls. In humans, plasma HDL SM was also decreased in chronically alcoholic individuals with or without liver disease, compared with nondrinkers. Based on these findings, it was concluded that long-term ethanol consumption significantly impaired cholesterol efflux function of HDL by decreasing its SM content [141]. These results are a truly interesting contribution to the search for a substitute for cholesterol efflux assays in large intervention studies.

\subsection{Pharmacological Agents}

Many pharmacological agents have been observed to exert an effect on HDL SM content. In this respect, after intraperitoneal insulin pump implantation, SM concentrations decreased in all lipoprotein fractions. As a result, the SM/PC ratio, an index of the surface rigidity of lipoproteins, decreased [142], a change that was not observed with continuous subcutaneous insulin infusions [143]. Administration of raloxifene, a selective estrogen receptor modulator, to postmenopausal women also decreased $\mathrm{HDL}_{2}$ SM [144], an effect that was not potentiated by combined administration of atorvastatin, an inhibitor of hydroxymethylglutaryl-CoA reductase [145], despite its reported SM-reducing properties. Another statin, rosuvastatin, was even more potent than atorvastatin regarding the latter effect [146].

SM-increasing action has also been reported. In this regard, fenofibrate, a hypocholesterolemic agent acting as ligand of the peroxisome proliferator-activated receptor $\alpha$, increased HDL SM [147-149], as did the administration of the antihypertensive captopril, an angiotensin-converting enzyme inhibitor, and the diuretic hydrochlorothiazide in hypertensive patients [150]. Contraceptives were also found to exert this effect. This change was most profound in women receiving preparations in which progestin was predominant; in contrast, in women receiving preparations with higher estrogen to progestin ratios, the SM/PC ratio actually declined [151,152]. On the other hand, androgens such as tibolone lowered HDL-cholesterol without modifying HDL SM [153]. These compositional changes in the phospholipid content of HDL may influence its capacity to promote cellular cholesterol efflux, as reported previously, and contribute to the atherogenicity of these agents. In fact, inhibition of de novo SM biosynthesis by myriocin, an inhibitor of serine palmitoyltransferase, resulted in decreased atherosclerosis in Apoe-deficient mice [154] and induction of APOA1 and LCAT activity [111].

Other agents such as ibuprofen, when added to HDL, induced an upfield chemical shift of SM in lipoprotein particles. This could be explained by changes in orientation of the phospholipid head group at the surface of the lipoprotein particles [155].

\subsection{Changes in HDL-SM Affected by Pathological Conditions}

The amount of SM present in HDL may be modified in several pathological circumstances, both in rare monogenic disorders and in common diseases. A threefold increase in the SM/PC ratio was found in plasma HDL in abetalipoproteinemia, with no changes in SM fatty acid composition [156-158]. Niemann-Pick disease types A and B caused by an acid sphingomyelinase deficiency due to mutations in the sphingomyelin phosphodiesterase- 1 gene. These patients have been reported to have a severe 
reduction in plasma HDL cholesterol [159-161] and SM-enriched HDL [162]. This abnormal HDL composition may cause a decrease in LCAT activity and a lack of HDL maturation [163,164], and was a consequence of a reduced cholesterol efflux [165]. In Tangier disease, the relative quantity of long-chain fatty acids (23 or more carbons) in serum SM was about 38\% lower than that of control sera [166].

Said changes are not only found in these low prevalence disorders, but in more common ailments, as well. In this regard, decreased content of HDL SM was observed in the acute-phase response [167], in hypoalphaliproteinemia [13] and in patients with triple-vessel coronary artery disease [168]. Decreased concentrations of HDL SM were also observed in diabetic women [169], while they were not observed in diabetic men [170]. A decreased SM level as compared to PC was found in renal patients on long-term maintenance hemodialysis [171]. Surprisingly, in cross-sectional analyses, type 1 diabetic patients with advanced kidney disease had high serum SM [172], and SM emerged as a significant biochemical covariate of urinary albumin excretion [173]. An increased HDL phospholipid concentration has been shown to be a valuable index in patients with multiple myeloma responding to therapy [174] or after periodontal treatment, as HDL phospholipids and the SM/PC ratio also increased in patients with periodontitis [175]. Higher HDL SM was observed in hypertensive patients [176].

Changes in HDL-SM have also been observed in several strains of knockout or transgenic animals. In this respect, increased SM content was observed in Abcal-deficient mice and these mice showed decreased phospholipid transfer protein and LCAT activities [177]. Increased HDL SM was also observed in Apoe-deficient mice due to reduced catabolic rate and increased production rates [178]. On the other hand, using recombinant adenovirus vectors containing human SM synthase 1 and 2, it was shown that HDL-SM content decreased due to enhanced clearance of these particles $[179,180]$. Changes in the SM/PC ratio were also observed in Pltp-deficient mice in association with a marked reduction in HDL levels [181]. Liver Sptlc2 deficiency decreased plasma HDL SM levels by 36\%, and increased PC levels, thus decreasing the SM/PC ratio compared with controls [182].

\section{Conclusions}

Sphingomyelin present in HDL modifies their properties by altering protein conformation and function, and exerts an effect on other enzymes, receptors, transporters, etc., involved in HDL metabolism. Its level is very dynamic and changes under physiological, pharmacological and pathological conditions. The HDL-SM association with cholesterol efflux is a promising field to be confirmed as a new biomarker in coronary heart disease. Furthermore, the existence of different species of SM based on the fatty acid residue on the sphingoid base and the selective presence of SM in some HDL particles open an important field focusing on isolating and characterizing types of SM in these lipoparticles and their relevance in health and disease. Thus, further studies are warranted to establish the value of all these parameters.

\section{Acknowledgments}

The work of these authors was supported by grants from CICYT-FEDER (SAF2010-14958), Redes FSE-DGA (B-69) and CIBER de Fisiopatología de la Obesidad y Nutrición (CIBEROBN) as an initiative of the ISCIII and FSE. We thank Martha Messman for her assistance in editing the manuscript. 


\section{Conflict of Interest}

The authors declare no conflict of interest.

\section{References}

1. Vaisar, T.; Pennathur, S.; Green, P.S.; Gharib, S.A.; Hoofnagle, A.N.; Cheung, M.C.; Byun, J.; Vuletic, S.; Kassim, S.; Singh, P.; et al. Shotgun proteomics implicates protease inhibition and complement activation in the antiinflammatory properties of HDL. J. Clin. Invest. 2007, 117, 746-756.

2. Lou-Bonafonte, J.M.; Fito, M.; Covas, M.I.; Farras, M.; Osada, J. HDL-related mechanisms of olive oil protection in cardiovascular disease. Curr. Vasc. Pharmacol. 2012, 10, 392-409.

3. Gotto, A.M., Jr. High-density lipoproteins: Biochemical and metabolic factors. Am. J. Cardiol. 1983, 52, 2B-4B.

4. Rosenson, R.S.; Brewer, H.B., Jr.; Chapman, M.J.; Fazio, S.; Hussain, M.M.; Kontush, A.; Krauss, R.M.; Otvos, J.D.; Remaley, A.T.; Schaefer, E.J. HDL measures, particle heterogeneity, proposed nomenclature, and relation to atherosclerotic cardiovascular events. Clin. Chem. 2011, 57, 392-410.

5. Kontush, A.; Therond, P.; Zerrad, A.; Couturier, M.; Negre-Salvayre, A.; de Souza, J.A.; Chantepie, S.; Chapman, M.J. Preferential sphingosine-1-phosphate enrichment and sphingomyelin depletion are key features of small dense HDL3 particles: Relevance to antiapoptotic and antioxidative activities. Arterioscler. Thromb. Vasc. Biol. 2007, 27, 1843-1849.

6. Hofer, G.; Lichtenberg, D.; Kostner, G.M.; Hermetter, A. Oxidation of fluorescent glycero- and sphingophospholipids in human plasma lipoproteins: Alkenylacyl subclasses are preferred targets. Clin. Biochem. 1996, 29, 445-450.

7. Chong, C.P.; Lin, T.Y.; Chang, C.L.; Yang, Y.L.; Tsai, M.H.; Yu, Y.S.; Liu, M.Y. Micellar electrokinetic chromatography profiles of human high-density lipoprotein phospholipids. Electrophoresis 2011, 32, 1241-1251.

8. Khovidhunkit, W.; Kim, M.S.; Memon, R.A.; Shigenaga, J.K.; Moser, A.H.; Feingold, K.R.; Grunfeld, C. Effects of infection and inflammation on lipid and lipoprotein metabolism: Mechanisms and consequences to the host. J. Lipid Res. 2004, 45, 1169-1196.

9. Navab, M.; Reddy, S.T.; van Lenten, B.J.; Anantharamaiah, G.M.; Fogelman, A.M. The role of dysfunctional HDL in atherosclerosis. J. Lipid Res. 2009, 50, S145-S149.

10. Hammad, S.M.; Pierce, J.S.; Soodavar, F.; Smith, K.J.; Al Gadban, M.M.; Rembiesa, B.; Klein, R.L.; Hannun, Y.A.; Bielawski, J.; Bielawska, A. Blood sphingolipidomics in healthy humans: Impact of sample collection methodology. J. Lipid Res. 2010, 51, 3074-3087.

11. Rodriguez, C.; Gonzalez-Diez, M.; Badimon, L.; Martinez-Gonzalez, J. Sphingosine-1-phosphate: A bioactive lipid that confers high-density lipoprotein with vasculoprotection mediated by nitric oxide and prostacyclin. Thromb. Haemost. 2009, 101, 665-673.

12. Hoofnagle, A.N.; Vaisar, T.; Mitra, P.; Chait, A. HDL lipids and insulin resistance. Curr. Diab. Rep. 2010, 10, 78-86. 
13. Yetukuri, L.; Soderlund, S.; Koivuniemi, A.; Seppanen-Laakso, T.; Niemela, P.S.; Hyvonen, M.; Taskinen, M.R.; Vattulainen, I.; Jauhiainen, M.; Oresic, M. Composition and lipid spatial distribution of HDL particles in subjects with low and high HDL-cholesterol. J. Lipid Res. 2010, 51, 2341-2351.

14. Moher, D.; Liberati, A.; Tetzlaff, J.; Altman, D.G.; The, P.G. Preferred reporting items for systematic reviews and meta-analyses: The PRISMA Statement. PLoS Med. 2009, 6, e1000097.

15. Skipski, V.P.; Barclay, M.; Barclay, R.K.; Fetzer, V.A.; Good, J.J.; Archibald, F.M. Lipid composition of human serum lipoproteins. Biochem. J. 1967, 104, 340-352.

16. Daerr, W.H.; Greten, H. In vitro modulation of the distribution of normal human plasma high density lipoprotein subfractions through the lecithin: Cholesterol acyltransferase reaction. Biochim. Biophys. Acta 1982, 710, 128-133.

17. Darr, W.H.; Windler, E.E.; Stephan, K.U.; Walli, A.K.; Greten, H. Characterization and catabolism of rat very high density lipoproteins. J. Lipid Res. 1985, 26, 672-683.

18. Davidson, W.S.; Sparks, D.L.; Lund-Katz, S.; Phillips, M.C. The molecular basis for the difference in charge between pre-beta- and alpha-migrating high density lipoproteins. J. Biol. Chem. 1994, 269, 8959-8965.

19. Marques-Vidal, P.; Jauhiainen, M.; Metso, J.; Ehnholm, C. Transformation of high density lipoprotein 2 particles by hepatic lipase and phospholipid transfer protein. Atherosclerosis 1997, 133, 87-95.

20. Maldonado, E.N.; Casanave, E.B.; Aveldano, M.I. Major plasma lipids and fatty acids in four HDL mammals. Comp. Biochem. Physiol. Part A 2002, 132, 297-303.

21. Blaton, V.; Vercaemst, R.; Rosseneu, M.; Mortelmans, J.; Jackson, R.L.; Gotto, A.M., Jr.; Peeters, H. Characterization of baboon plasma high-density lipoproteins and of their major apoproteins. Biochemistry 1977, 16, 2157-2163.

22. McConathy, W.J.; Alaupovic, P. Studies on the isolation and partial characterization of apolipoprotein D and lipoprotein D of human plasma. Biochemistry 1976, 15, 515-520.

23. Krimbou, L.; Tremblay, M.; Jacques, H.; Davignon, J.; Cohn, J.S. In vitro factors affecting the concentration of gamma-LpE in human plasma. J. Lipid Res. 1998, 39, 861-872.

24. Duverger, N.; Ghalim, N.; Theret, N.; Fruchart, J.C.; Castro, G. Lipoproteins containing apolipoprotein A-IV: Composition and relation to cholesterol esterification. Biochim. Biophys. Acta 1994, 1211, 23-28.

25. Atmeh, R.F.; Kana'an, B.M.; Massad, T.T. Isolation of high density lipoprotein subclasses by electrofiltration and their chemical components. Prep. Biochem. Biotechnol. 2009, 39, 248-265.

26. Nanjee, M.N.; Cooke, C.J.; Olszewski, W.L.; Miller, N.E. Lipid and apolipoprotein concentrations in prenodal leg lymph of fasted humans. Associations with plasma concentrations in normal subjects, lipoprotein lipase deficiency, and LCAT deficiency. J. Lipid Res. 2000, 41, $1317-1327$.

27. Sloop, C.H.; Dory, L.; Roheim, P.S. Interstitial fluid lipoproteins. J. Lipid Res. 1987, 28, $225-237$.

28. Worgall, T.S. Sphingolipid synthetic pathways are major regulators of lipid homeostasis. Adv. Exp. Med. Biol. 2011, 721, 139-148.

29. Hussain, M.M.; Jin, W.; Jiang, X.C. Mechanisms involved in cellular ceramide homeostasis. Nutr. Metab. 2012, 9, 71. 
30. Maric, J.; Kiss, R.S.; Franklin, V.; Marcel, Y.L. Intracellular lipidation of newly synthesized apolipoprotein A-I in primary murine hepatocytes. J. Biol. Chem. 2005, 280, 39942-39949.

31. Subbaiah, P.V.; Gesquiere, L.R.; Wang, K. Regulation of the selective uptake of cholesteryl esters from high density lipoproteins by sphingomyelin. J. Lipid Res. 2005, 46, 2699-2705.

32. Bielicki, J.K.; Johnson, W.J.; Glick, J.M.; Rothblat, G.H. Efflux of phospholipid from fibroblasts with normal and elevated levels of cholesterol. Biochim. Biophys. Acta 1991, 1085, 7-14.

33. Zhang, W.; Asztalos, B.; Roheim, P.S.; Wong, L. Characterization of phospholipids in pre-alpha HDL: Selective phospholipid efflux with apolipoprotein A-I. J. Lipid Res. 1998, 39, 1601-1607.

34. Sorci-Thomas, M.G.; Owen, J.S.; Fulp, B.; Bhat, S.; Zhu, X.; Parks, J.S.; Shah, D.; Jerome, W.G.; Gerelus, M.; Zabalawi, M.; et al. Nascent high density lipoproteins formed by ABCA1 resemble lipid rafts and are structurally organized by three apoA-I monomers. J. Lipid Res. 2012, 53, 1890-1909.

35. Choi, H.Y.; Karten, B.; Chan, T.; Vance, J.E.; Greer, W.L.; Heidenreich, R.A.; Garver, W.S.; Francis, G.A. Impaired ABCA1-dependent lipid efflux and hypoalphalipoproteinemia in human Niemann-Pick type C disease. J. Biol. Chem. 2003, 278, 32569-32577.

36. Toledo, J.D.; Cabaleiro, L.V.; Garda, H.A.; Gonzalez, M.C. Effect of reconstituted discoidal high-density lipoproteins on lipid mobilization in RAW 264.7 and CHOK1 cells. J. Cell. Biochem. 2011, 113, 1208-1216.

37. Savion, N.; Greemland, M.; Kotev-Emeth, S.; Thilo-Korner, D.G. Metabolism of cholesterol and phospholipids in cultured human vascular smooth muscle cells: Differences between artery and vein-derived cells and the effect of oxygen partial pressure. Eur. J. Cell. Biol. 1991, 55, 305-311.

38. Francis, G.A.; Tsujita, M.; Terry, T.L. Apolipoprotein AI efficiently binds to and mediates cholesterol and phospholipid efflux from human but not rat aortic smooth muscle cells. Biochemistry 1999, 38, 16315-16322.

39. Massey, J.B.; Hickson-Bick, D.; Via, D.P.; Gotto, A.M., Jr.; Pownall, H.J. Fluorescence assay of the specificity of human plasma and bovine liver phospholipid transfer proteins. Biochim. Biophys. Acta 1985, 835, 124-131.

40. Schifferer, R.; Liebisch, G.; Bandulik, S.; Langmann, T.; Dada, A.; Schmitz, G. ApoA-I induces a preferential efflux of monounsaturated phosphatidylcholine and medium chain sphingomyelin species from a cellular pool distinct from HDL(3) mediated phospholipid efflux. Biochim. Biophys. Acta 2007, 1771, 853-863.

41. Fukuda, M.; Nakano, M.; Sriwongsitanont, S.; Ueno, M.; Kuroda, Y.; Handa, T. Spontaneous reconstitution of discoidal HDL from sphingomyelin-containing model membranes by apolipoprotein A-I. J. Lipid Res. 2007, 48, 882-889.

42. Sparks, D.L.; Frank, P.G.; Neville, T.A. Effect of the surface lipid composition of reconstituted LPA-I on apolipoprotein A-I structure and lecithin: Cholesterol acyltransferase activity. Biochim. Biophys. Acta 1998, 1390, 160-172.

43. Rye, K.A.; Hime, N.J.; Barter, P.J. The influence of sphingomyelin on the structure and function of reconstituted high density lipoproteins. J. Biol. Chem. 1996, 271, 4243-4250.

44. Lottin, H.; Motta, C.; Simard, G. Differential effects of glycero- and sphingo-phospholipolysis on human high-density lipoprotein fluidity. Biochim. Biophys. Acta 1996, 1301, 127-132. 
45. Slotte, J.P.; Gronberg, L. Oxidation of cholesterol in low density and high density lipoproteins by cholesterol oxidase. J. Lipid Res. 1990, 31, 2235-2242.

46. Subbaiah, P.V.; Subramanian, V.S.; Wang, K. Novel physiological function of sphingomyelin in plasma. Inhibition of lipid peroxidation in low density lipoproteins. J. Biol. Chem. 1999, 274, 36409-36414.

47. Assmann, G.; Sokoloski, E.A.; Brewer, H.B., Jr. 31P nuclear magnetic resonance spectroscopy of native and recombined lipoproteins. Proc. Natl. Acad. Sci. USA 1974, 71, 549-553.

48. Assmann, G.; Highet, R.J.; Sokoloski, E.A.; Brewer, H.B., Jr. 13C nuclear magnetic resonance spectroscopy of native and recombined lipoproteins. Proc. Natl. Acad. Sci. USA 1974, 71, 3701-3705.

49. Stoffel, W.; Metz, P. Chemical studies on the structure of human serum high-density lipoprotein (HDL). Photochemical crosslinking of azido-labelled lipids in HDL. Hoppe-Seyler's. Z. Physiol. Chem. 1982, 363, 19-31.

50. Tam, S.P.; Breckenridge, W.C. Apolipoprotein and lipid distribution between vesicles and HDL-like particles formed during lipolysis of human very low density lipoproteins by perfused rat heart. J. Lipid Res. 1983, 24, 1343-1357.

51. Stoffel, W.; Darr, W.; Salm, K.P. Lipid-protein interactions between human apolipoprotein A-I and defined sphingomyelin species. A 13C-NMR spectroscopic study. Hoppe-Seyler's Z. Physiol. Chem. 1977, 358, 1-11.

52. Stoffel, W.; Darr, W.; Salm, K.P. Chemical proof of lipid-protein interactions by crosslinking photosensitive lipids to apoproteins. Intermolecular cross-linkage between high-density apolipoprotein A-I and lecithins and sphingomyelins. Hoppe.-Seyler's Z. Physiol. Chem. 1977, $358,453-462$.

53. Swaney, J.B. Reconstitution of apolipoprotein A-I from human high density lipoprotein with bovine brain sphingomyelin. J. Biol. Chem. 1983, 258, 1254-1259.

54. Assmann, G.; Brewer, H.B., Jr. Lipid-protein interactions in high density lipoproteins. Proc. Natl. Acad. Sci. USA 1974, 71, 989-993.

55. Stoffel, W.; Zierenberg, O.; Tunggal, B.; Schreiber, E. 13C nuclear magnetic resonance spectroscopic evidence for hydrophobic lipid-protein interactions in human high density lipoproteins. Proc. Natl. Acad. Sci. USA 1974, 71, 3696-3700.

56. Ibdah, J.A.; Lund-Katz, S.; Phillips, M.C. Molecular packing of high-density and low-density lipoprotein surface lipids and apolipoprotein A-I binding. Biochemistry 1989, 28, 1126-1133.

57. Forte, T.M.; Bielicki, J.K.; Goth-Goldstein, R.; Selmek, J.; McCall, M.R. Recruitment of cell phospholipids and cholesterol by apolipoproteins A-II and A-I: Formation of nascent apolipoprotein-specific HDL that differ in size, phospholipid composition, and reactivity with LCAT. J. Lipid Res. 1995, 36, 148-157.

58. Molotkovsky, J.G.; Manevich, Y.M.; Gerasimova, E.N.; Molotkovskaya, I.M.; Polessky, V.A.; Bergelson, L.D. Differential study of phosphatidylcholine and sphingomyelin in human high-density lipoproteins with lipid-specific fluorescent probes. Eur. J. Biochem. 1982, 122, 573-579. 
59. Lindholm, E.M.; Bielicki, J.K.; Curtiss, L.K.; Rubin, E.M.; Forte, T.M. Deletion of amino acids Glu146->Arg160 in human apolipoprotein A-I (ApoA-ISeattle) alters lecithin: Cholesterol acyltransferase activity and recruitment of cell phospholipid. Biochemistry 1998, 37, 4863-4868.

60. Fox, T.E.; Bewley, M.C.; Unrath, K.A.; Pedersen, M.M.; Anderson, R.E.; Jung, D.Y.; Jefferson, L.S.; Kim, J.K.; Bronson, S.K.; Flanagan, J.M.; et al. Circulating sphingolipid biomarkers in models of type 1 diabetes. J. Lipid Res. 2011, 52, 509-517.

61. Laurila, P.P.; Surakka, I.; Sarin, A.P.; Yetukuri, L.; Hyotylainen, T.; Soderlund, S.; Naukkarinen, J.; Tang, J.; Kettunen, J.; Mirel, D.B.; et al. Genomic, transcriptomic, and lipidomic profiling highlights the role of inflammation in individuals with low high-density lipoprotein cholesterol. Arterioscler. Thromb. Vasc. Biol. 2013, 33, 847-857.

62. Kuksis, A.; Myher, J.J.; Geher, K.; Breckenridge, W.C.; Jones, G.J.; Little, J.A. Lipid class and molecular species interrelationships among plasma lipoproteins of normolipemic subjects. J. Chromatogr. 1981, 224, 1-23.

63. Myher, J.J.; Kuksis, A.; Breckenridge, W.C.; Little, J.A. Differential distribution of sphingomyelins among plasma lipoprotein classes. Can. J. Biochem. 1981, 59, 626-636.

64. Kuksis, A.; Myher, J.J.; Geher, K.; Breckenridge, W.C.; Little, J.A. Lipid class and molecular species interrelationships among plasma lipoproteins of type III and type IV hyperlipemic subjects. J. Chromatogr. 1982, 230, 231-252.

65. Breckenridge, W.C.; Dolphin, P.J.; Tan, M.H. Distribution of the molecular species of phospholipids in human umbilical cord blood. Lipids 1984, 19, 337-340.

66. Wu, C.Y.; Peng, Y.N.; Chiu, J.H.; Ho, Y.L.; Chong, C.P.; Yang, Y.L.; Liu, M.Y. Characterization of in vitro modified human high-density lipoprotein particles and phospholipids by capillary zone electrophoresis and LC ESI-MS. J. Chromatogr. B 2009, 877, 3495-3505.

67. Stubiger, G.; Aldover-Macasaet, E.; Bicker, W.; Sobal, G.; Willfort-Ehringer, A.; Pock, K.; Bochkov, V.; Widhalm, K.; Belgacem, O. Targeted profiling of atherogenic phospholipids in human plasma and lipoproteins of hyperlipidemic patients using MALDI-QIT-TOF-MS/MS. Atherosclerosis 2012, 224, 177-186.

68. Fernando-Warnakulasuriya, G.J.; Eckerson, M.L.; Clark, W.A.; Wells, M.A. Lipoprotein metabolism in the suckling rat: Characterization of plasma and lymphatic lipoproteins. J. Lipid Res. 1983, 24, 1626-1638.

69. Bentejac, M.; Bugaut, M.; Delachambre, M.C.; Lecerf, J. Utilization of high-density lipoprotein sphingomyelin by the developing and mature brain in the rat. J. Neurochem. 1989, 52, 1495-1500.

70. Bentejac, M.; Bugaut, M.; Delachambre, M.C.; Lecerf, J. Time-course of utilization of (stearic or lignoceric acid)sphingomyelin from high-density lipoprotein by rat tissues. Biochim. Biophys. Acta 1990, 1043, 134-142.

71. Bamberger, M.; Lund-Katz, S.; Phillips, M.C.; Rothblat, G.H. Mechanism of the hepatic lipase induced accumulation of high-density lipoprotein cholesterol by cells in culture. Biochemistry 1985, 24, 3693-3701.

72. Engelmann, B.; Kogl, C.; Kulschar, R.; Schaipp, B. Transfer of phosphatidylcholine, phosphatidylethanolamine and sphingomyelin from low- and high-density lipoprotein to human platelets. Biochem. J. 1996, 315, 781-789. 
73. Bentejac, M.; Lecerf, J.; Bugaut, M.; Delachambre, M.C. Turnover and uptake of double-labelled high-density lipoprotein sphingomyelin in the adult rat. Biochim. Biophys. Acta 1988, 959, 349-360.

74. Bentejac, M.; Bugaut, M.; Delachambre, M.C.; Lecerf, J. Metabolic fate of sphingomyelin of high-density lipoprotein in rat plasma. Lipids 1990, 25, 653-660.

75. Illingworth, D.R.; Portman, O.W. Exchange of phospholipids between low and high density lipoproteins of squirrel monkeys. J. Lipid Res. 1972, 13, 220-227.

76. Fournier, N.; Paul, J.L.; Atger, V.; Cogny, A.; Soni, T.; de la Llera-Moya, M.; Rothblat, G.; Moatti, N. HDL phospholipid content and composition as a major factor determining cholesterol efflux capacity from Fu5AH cells to human serum. Arterioscler. Thromb. Vasc. Biol. 1997, 17, 2685-2691.

77. Horter, M.J.; Sondermann, S.; Reinecke, H.; Bogdanski, J.; Woltering, A.; Kerber, S.; Breithardt, G.; Assmann, G.; Von Eckardstein, A. Associations of HDL phospholipids and paraoxonase activity with coronary heart disease in postmenopausal women. Acta Physiol. Scand. 2002, 176, 123-130.

78. Hergenc, G.; Onat, A.; Sari, I.; Yazici, M.; Eryonucu, B.; Can, G. Serum total and high-density lipoprotein phospholipid levels in a population-based study and relationship to risk of metabolic syndrome and coronary disease. Angiology 2008, 59, 26-35.

79. Stein, Y.; Glangeaud, M.C.; Fainaru, M.; Stein, O. The removal of cholesterol from aortic smooth muscle cells in culture and Landschutz ascites cells by fractions of human high-density apolipoprotein. Biochim. Biophys. Acta 1975, 380, 106-118.

80. Stein, O.; Vanderhoek, J.; Stein, Y. Cholesterol content and sterol synthesis in human skin fibroblasts and rat aortic smooth muscle cells exposed to lipoprotein-depleted serum and high density apolipoprotein/phospholipid mixtures. Biochim. Biophys. Acta 1976, 431, 347-358.

81. Stein, O.; Coetzee, G.A.; Stein, Y. Modulation of cytoplasmic cholesteryl ester of smooth muscle cells in culture derived from rat, rabbit and bovine aorta. Biochim. Biophys. Acta 1980, 620, 538-549.

82. Stein, O.; Dabach, Y.; Hollander, G.; Halperin, G.; Oette, K.; Stein, Y. Cholesterol removal by peritoneal lavage with phospholipid-HDL apoprotein mixtures in hypercholesterolemic hamsters. Biochim. Biophys. Acta 1989, 1006, 144-146.

83. Zhao, Y.; Sparks, D.L.; Marcel, Y.L. Effect of the apolipoprotein A-I and surface lipid composition of reconstituted discoidal HDL on cholesterol efflux from cultured fibroblasts. Biochemistry 1996, 35, 16510-16518.

84. Swaney, J.B. Membrane cholesterol uptake by recombinant lipoproteins. Chem. Phys. Lipids 1985, 37, 317-327.

85. Jian, B.; de la Llera-Moya, M.; Royer, L.; Rothblat, G.; Francone, O.; Swaney, J.B. Modification of the cholesterol efflux properties of human serum by enrichment with phospholipid. J. Lipid Res. 1997, 38, 734-744.

86. Haidar, B.; Mott, S.; Boucher, B.; Lee, C.Y.; Marcil, M.; Genest, J., Jr. Cellular cholesterol efflux is modulated by phospholipid-derived signaling molecules in familial HDL deficiency/Tangier disease fibroblasts. J. Lipid Res. 2001, 42, 249-257.

87. Ma, C.I.; Beckstead, J.A.; Thompson, A.; Hafiane, A.; Wang, R.H.; Ryan, R.O.; Kiss, R.S. Tweaking the cholesterol efflux capacity of reconstituted HDL. Biochem. Cell. Biol. 2012, 90, 636-645. 
88. Kobayashi, A.; Takanezawa, Y.; Hirata, T.; Shimizu, Y.; Misasa, K.; Kioka, N.; Arai, H.; Ueda, K.; Matsuo, M. Efflux of sphingomyelin, cholesterol, and phosphatidylcholine by ABCG1. J. Lipid Res. 2006, 47, 1791-1802.

89. Kimura, Y.; Morita, S.Y.; Matsuo, M.; Ueda, K. Mechanism of multidrug recognition by MDR1/ABCB1. Cancer Sci. 2007, 98, 1303-1310.

90. Liu, L.; Bortnick, A.E.; Nickel, M.; Dhanasekaran, P.; Subbaiah, P.V.; Lund-Katz, S.; Rothblat, G.H.; Phillips, M.C. Effects of apolipoprotein A-I on ATP-binding cassette transporter A1-mediated efflux of macrophage phospholipid and cholesterol: Formation of nascent high density lipoprotein particles. J. Biol. Chem. 2003, 278, 42976-42984.

91. Hirayama, H.; Kimura, Y.; Kioka, N.; Matsuo, M.; Ueda, K. ATPase activity of human ABCG1 is stimulated by cholesterol and sphingomyelin. J. Lipid Res. 2013, 54, 496-502.

92. Sano, O.; Kobayashi, A.; Nagao, K.; Kumagai, K.; Kioka, N.; Hanada, K.; Ueda, K.; Matsuo, M. Sphingomyelin-dependence of cholesterol efflux mediated by ABCG1. J. Lipid Res. 2007, 48, 2377-2384.

93. Miller, M.; Zhan, M. Genetic determinants of low high-density lipoprotein cholesterol. Curr. Opin. Cardiol. 2004, 19, 380-384.

94. Marmillot, P.; Patel, S.; Lakshman, M.R. Reverse cholesterol transport is regulated by varying fatty acyl chain saturation and sphingomyelin content in reconstituted high-density lipoproteins. Metabolism 2007, 56, 251-259.

95. Sanchez, S.A.; Tricerri, M.A.; Gratton, E. Interaction of high density lipoprotein particles with membranes containing cholesterol. J. Lipid Res. 2007, 48, 1689-1700.

96. Gold, J.C.; Phillips, M.C. Effects of membrane lipid composition on the kinetics of cholesterol exchange between lipoproteins and different species of red blood cells. Biochim. Biophys. Acta 1990, 1027, 85-92.

97. Slotte, J.P.; Tenhunen, J.; Porn, I. Effects of sphingomyelin degradation on cholesterol mobilization and efflux to high-density lipoproteins in cultured fibroblasts. Biochim. Biophys. Acta 1990, 1025, 152-156.

98. Porn, M.I.; Ares, M.P.; Slotte, J.P. Degradation of plasma membrane phosphatidylcholine appears not to affect the cellular cholesterol distribution. J. Lipid Res. 1993, 34, 1385-1392.

99. Ito, J.; Nagayasu, Y.; Yokoyama, S. Cholesterol-sphingomyelin interaction in membrane and apolipoprotein-mediated cellular cholesterol efflux. J. Lipid Res. 2000, 41, 894-904.

100. Ito, J.; Nagayasu, Y.; Ueno, S.; Yokoyama, S. Apolipoprotein-mediated cellular lipid release requires replenishment of sphingomyelin in a phosphatidylcholine-specific phospholipase C-dependent manner. J. Biol. Chem. 2002, 277, 44709-44714.

101. Nagao, K.; Takahashi, K.; Hanada, K.; Kioka, N.; Matsuo, M.; Ueda, K. Enhanced apoA-I-dependent cholesterol efflux by ABCA1 from sphingomyelin-deficient Chinese hamster ovary cells. J. Biol. Chem. 2007, 282, 14868-14874.

102. Yamauchi, Y.; Hayashi, M.; Abe-Dohmae, S.; Yokoyama, S. Apolipoprotein A-I activates protein kinase $\mathrm{C}$ alpha signaling to phosphorylate and stabilize ATP binding cassette transporter A1 for the high density lipoprotein assembly. J. Biol. Chem. 2003, 278, 47890-47897.

103. Takahashi, K.; Kimura, Y.; Kioka, N.; Matsuo, M.; Ueda, K. Purification and ATPase activity of human ABCA1. J. Biol. Chem. 2006, 281, 10760-10768. 
104. Panousis, C.G.; Zuckerman, S.H. Interferon-gamma induces downregulation of Tangier disease gene (ATP-binding-cassette transporter 1) in macrophage-derived foam cells. Arterioscler. Thromb. Vasc. Biol. 2000, 20, 1565-1571.

105. Tamehiro, N.; Zhou, S.; Okuhira, K.; Benita, Y.; Brown, C.E.; Zhuang, D.Z.; Latz, E.; Hornemann, T.; von Eckardstein, A.; Xavier, R.J.; et al. SPTLC1 binds ABCA1 to negatively regulate trafficking and cholesterol efflux activity of the transporter. Biochemistry 2008, 47, 6138-6147.

106. Allen, T.M. A study of phospholipid interactions between high-density lipoproteins and small unilamellar vesicles. Biochim. Biophys. Acta 1981, 640, 385-397.

107. Sweeny, S.A.; Jonas, A. Substrate specificity of human plasma phospholipid transfer protein. Biochim. Biophys. Acta 1985, 835, 279-290.

108. Singh, D.K.; Gesquiere, L.R.; Subbaiah, P.V. Role of sphingomyelin and ceramide in the regulation of the activity and fatty acid specificity of group $\mathrm{V}$ secretory phospholipase A2. Arch. Biochem. Biophys. 2007, 459, 280-287.

109. Subbaiah, P.V.; Liu, M. Role of sphingomyelin in the regulation of cholesterol esterification in the plasma lipoproteins. Inhibition of lecithin-cholesterol acyltransferase reaction. J. Biol. Chem. 1993, 268, 20156-20163.

110. Subbaiah, P.V.; Jiang, X.C.; Belikova, N.A.; Aizezi, B.; Huang, Z.H.; Reardon, C.A. Regulation of plasma cholesterol esterification by sphingomyelin: Effect of physiological variations of plasma sphingomyelin on lecithin-cholesterol acyltransferase activity. Biochim. Biophys. Acta 2012, 1821, 908-913.

111. Park, T.S.; Panek, R.L.; Rekhter, M.D.; Mueller, S.B.; Rosebury, W.S.; Robertson, A.; Hanselman, J.C.; Kindt, E.; Homan, R.; Karathanasis, S.K. Modulation of lipoprotein metabolism by inhibition of sphingomyelin synthesis in ApoE knockout mice. Atherosclerosis 2006, 189, 264-272.

112. Gesquiere, L.; Cho, W.; Subbaiah, P.V. Role of group IIa and group V secretory phospholipases A(2) in the metabolism of lipoproteins. Substrate specificities of the enzymes and the regulation of their activities by sphingomyelin. Biochemistry 2002, 41, 4911-4920.

113. Singh, D.K.; Subbaiah, P.V. Modulation of the activity and arachidonic acid selectivity of group X secretory phospholipase A2 by sphingolipids. J. Lipid Res. 2007, 48, 683-692.

114. Nilsson, A.; Duan, R.D. Absorption and lipoprotein transport of sphingomyelin. J. Lipid Res. 2006, 47, 154-171.

115. Chajek, T.; Aron, L.; Fielding, C.J. Interaction of lecithin:cholesterol acyltransferase and cholesteryl ester transfer protein in the transport of cholesteryl ester into sphingomyelin liposomes. Biochemistry 1980, 19, 3673-3677.

116. Bolin, D.J.; Jonas, A. Sphingomyelin inhibits the lecithin-cholesterol acyltransferase reaction with reconstituted high density lipoproteins by decreasing enzyme binding. J. Biol. Chem. 1996, 271, 19152-19158.

117. Lee, J.Y.; Badeau, R.M.; Mulya, A.; Boudyguina, E.; Gebre, A.K.; Smith, T.L.; Parks, J.S. Functional LCAT deficiency in human apolipoprotein A-I transgenic, SR-BI knockout mice. J. Lipid Res. 2007, 48, 1052-1061. 
118. Rodrigueza, W.V.; Thuahnai, S.T.; Temel, R.E.; Lund-Katz, S.; Phillips, M.C.; Williams, D.L. Mechanism of scavenger receptor class B type I-mediated selective uptake of cholesteryl esters from high density lipoprotein to adrenal cells. J. Biol. Chem. 1999, 274, 20344-20350.

119. Rhainds, D.; Bourgeois, P.; Bourret, G.; Huard, K.; Falstrault, L.; Brissette, L. Localization and regulation of SR-BI in membrane rafts of HepG2 cells. J. Cell. Sci. 2004, 117, 3095-3105.

120. Thuahnai, S.T.; Lund-Katz, S.; Williams, D.L.; Phillips, M.C. Scavenger receptor class B, type I-mediated uptake of various lipids into cells. Influence of the nature of the donor particle interaction with the receptor. J. Biol. Chem. 2001, 276, 43801-43808.

121. Yancey, P.G.; de la Llera-Moya, M.; Swarnakar, S.; Monzo, P.; Klein, S.M.; Connelly, M.A.; Johnson, W.J.; Williams, D.L.; Rothblat, G.H. High density lipoprotein phospholipid composition is a major determinant of the bi-directional flux and net movement of cellular free cholesterol mediated by scavenger receptor BI. J. Biol. Chem. 2000, 275, 36596-36604.

122. Werder, M.; Han, C.H.; Wehrli, E.; Bimmler, D.; Schulthess, G.; Hauser, H. Role of scavenger receptors SR-BI and CD36 in selective sterol uptake in the small intestine. Biochemistry 2001, 40, 11643-11650.

123. Urban, S.; Zieseniss, S.; Werder, M.; Hauser, H.; Budzinski, R.; Engelmann, B. Scavenger receptor BI transfers major lipoprotein-associated phospholipids into the cells. J. Biol. Chem. 2000, 275, 33409-33415.

124. Berrougui, H.; Khalil, A. Age-associated decrease of high-density lipoprotein-mediated reverse cholesterol transport activity. Rejuvenation Res. 2009, 12, 117-126.

125. Berrougui, H.; Isabelle, M.; Cloutier, M.; Grenier, G.; Khalil, A. Age-related impairment of HDL-mediated cholesterol efflux. J. Lipid Res. 2007, 48, 328-336.

126. Schriewer, H.; Gunnewig, V.; Assmann, G. HDL sphingomyelin determinations in normal individuals and patients with type IV-hyperlipoproteinaemia. J. Clin. Chem. Clin. Biochem. 1983, 21, 139-143.

127. Deevska, G.M.; Sunkara, M.; Morris, A.J.; Nikolova-Karakashian, M.N. Characterization of secretory sphingomyelinase activity, lipoprotein sphingolipid content and LDL aggregation in ldlr-/- mice fed on a high-fat diet. Biosci. Rep. 2012, 32, 479-490.

128. Bladergroen, B.A.; Beynen, A.C.; Geelen, M.J. Dietary pectin lowers sphingomyelin concentration in VLDL and raises hepatic sphingomyelinase activity in rats. J. Nutr. 1999, 129, 628-633.

129. Geelen, M.J.; van Hoorn, D.; Beynen, A.C. Consumption of casein instead of soybean protein produces a transient rise in the concentration of sphingomyelin in VLDL in rats. J. Nutr. 1999, 129, 2119-2122.

130. Geelen, M.J.; Beynen, A.C. Consumption of olive oil has opposite effects on plasma total cholesterol and sphingomyelin concentrations in rats. Br. J. Nutr. 2000, 83, 541-547.

131. Martínez-Beamonte, R.; Navarro, M.A.; Acin, S.; Guillén, N.; Barranquero, C.; Arnal, C.; Surra, J.; Osada, J. Postprandial changes in high density lipoproteins in rats subjected to gavage administration of virgin olive oil. PLoS One 2013, doi:10.1371/journal.pone.0055231.

132. Li, Z.; Basterr, M.J.; Hailemariam, T.K.; Hojjati, M.R.; Lu, S.; Liu, J.; Liu, R.; Zhou, H.; Jiang, X.C. The effect of dietary sphingolipids on plasma sphingomyelin metabolism and atherosclerosis. Biochim. Biophys. Acta 2005, 1735, 130-134. 
133. Vesper, H.; Schmelz, E.M.; Nikolova-Karakashian, M.N.; Dillehay, D.L.; Lynch, D.V.; Merrill, A.H., Jr. Sphingolipids in food and the emerging importance of sphingolipids to nutrition. J. Nutr. 1999, 129, 1239-1250.

134. Gerasimova, E.; Perova, N.; Ozerova, I.; Polessky, V.; Metelskaya, V.; Sherbakova, I.; Levachev, M.; Kulakova, S.; Nikitin, Y.; Astakhova, T. The effect of dietary n-3 polyunsaturated fatty acids on HDL cholesterol in Chukot residents vs muscovites. Lipids 1991, 26, 261-265.

135. Myher, J.J.; Kuksis, A.; Shepherd, J.; Packard, C.J.; Morrisett, J.D.; Taunton, O.D.; Gotto, A.M. Effect of saturated and unsaturated fat diets on molecular species of phosphatidylcholine and sphingomyelin of human plasma lipoproteins. Biochim. Biophys. Acta 1981, 666, 110-119.

136. Sola, R.; Baudet, M.F.; Motta, C.; Maille, M.; Boisnier, C.; Jacotot, B. Effects of dietary fats on the fluidity of human high-density lipoprotein: influence of the overall composition and phospholipid fatty acids. Biochim. Biophys. Acta 1990, 1043, 43-51.

137. Ottestad, I.; Hassani, S.; Borge, G.I.; Kohler, A.; Vogt, G.; Hyotylainen, T.; Oresic, M.; Bronner, K.W.; Holven, K.B.; Ulven, S.M.; Myhrstad, M.C. Fish oil supplementation alters the plasma lipidomic profile and increases long-chain PUFAs of phospholipids and triglycerides in healthy subjects. PLoS One 2012, 7, e42550.

138. Tynkkynen, T.; Mursu, J.; Nurmi, T.; Tuppurainen, K.; Laatikainen, R.; Soininen, P. NMR protocol for determination of oxidation susceptibility of serum lipids and application of the protocol to a chocolate study. Metabolomics 2012, 8, 386-398.

139. Floegel, A.; Stefan, N.; Yu, Z.; Muhlenbruch, K.; Drogan, D.; Joost, H.G.; Fritsche, A.; Haring, H.U.; Hrabe de Angelis, M.; Peters, A.; et al. Identification of serum metabolites associated with risk of type 2 diabetes using a targeted metabolomic approach. Diabetes 2013, 62, 639-648.

140. Schriewer, H.; Gunnewig, V.; Jung, K.; Assmann, G. The influence of a $100 \mathrm{~km}$ run on the composition of HDL. J. Clin. Chem. Clin. Biochem. 1982, 20, 533-536.

141. Marmillot, P.; Munoz, J.; Patel, S.; Garige, M.; Rosse, R.B.; Lakshman, M.R. Long-term ethanol consumption impairs reverse cholesterol transport function of high-density lipoproteins by depleting high-density lipoprotein sphingomyelin both in rats and in humans. Metabolism 2007, 56, 947-953.

142. Bagdade, J.D.; Dunn, F.L. Improved lipoprotein surface and core lipid composition following intraperitoneal insulin delivery in insulin-dependent diabetes mellitus. Diab. Metab. 1996, 22, 420-426.

143. Bagdade, J.D.; Helve, E.; Taskinen, M.R. Effects of continuous insulin infusion therapy on lipoprotein surface and core lipid composition in insulin-dependent diabetes mellitus. Metabolism 1991, 40, 445-449.

144. Piperi, C.; Kalofoutis, C.; Papapanagiotou, A.; Skenderi, C.; Kalofoutis, A. Comparative analysis of oestrogen and raloxifene effects on the phospholipid composition of high density lipoproteins in healthy postmenopausal women. J. Obstet. Gynaecol. 2004, 24, 52-57.

145. Piperi, C.; Kalofoutis, C.; Skenderi, K.; Economidou, O.; Kalofoutis, A. Beneficial effects of raloxifene and atorvastatin on serum lipids and HDL phospholipids levels of postmenopausal women. J. Obstet. Gynaecol. 2004, 24, 414-419. 
146. Bergheanu, S.C.; Reijmers, T.; Zwinderman, A.H.; Bobeldijk, I.; Ramaker, R.; Liem, A.H.; van der Greef, J.; Hankemeier, T.; Jukema, J.W. Lipidomic approach to evaluate rosuvastatin and atorvastatin at various dosages: Investigating differential effects among statins. Curr. Med. Res. Opin. 2008, 24, 2477-2487.

147. Perova, N.V.; Ozerova, I.N.; Paramonova, I.V.; Olfer'ev, A.M.; Akhmedzhanov, N.M.; Pavlova, L.I.; Oganov, R.G. Phospholipid composition of high-density lipoproteins reflects lipolysis of triglyceride-rich lipoproteins during hyperlipidemia. Bull. Exp. Biol. Med. 2001, 131, 321-324.

148. Hammad, S.M. Blood sphingolipids in homeostasis and pathobiology. Adv. Exp. Med. Biol. 2011, 721, 57-66.

149. Yetukuri, L.; Huopaniemi, I.; Koivuniemi, A.; Maranghi, M.; Hiukka, A.; Nygren, H.; Kaski, S.; Taskinen, M.R.; Vattulainen, I.; Jauhiainen, M.; et al. High density lipoprotein structural changes and drug response in lipidomic profiles following the long-term fenofibrate therapy in the FIELD substudy. PLoS One 2011, 6, e23589.

150. Bagdade, J.D.; Buchanan, W.F.; Pollare, T.; Lithell, H. Effects of hydrochlorothiazide and captopril on lipoprotein lipid composition in patients with essential hypertension. Eur. J. Clin. Pharmacol. 1996, 49, 355-359.

151. Bagdade, J.D.; Subbaiah, P.V. Influence of low estrogen-containing oral contraceptives on lipoprotein phospholipid composition and mononuclear cell membrane fluidity. J. Clin. Endocrinol. Metab. 1988, 66, 857-861.

152. Papapanagiotou, A.; Koufali, M.M.; Zachari, A.; Charalabidou, C.; Kalofoutis, A. Effects of hormone replacement therapy on the phospholipid composition of high density lipoproteins in postmenopausal women. J. Obstet. Gynaecol. 2001, 21, 56-61.

153. von Eckardstein, A.; Crook, D.; Elbers, J.; Ragoobir, J.; Ezeh, B.; Helmond, F.; Miller, N.; Dieplinger, H.; Bennink, H.C.; Assmann, G. Tibolone lowers high density lipoprotein cholesterol by increasing hepatic lipase activity but does not impair cholesterol efflux. Clin. Endocrinol. 2003, 58, 49-58.

154. Park, T.S.; Panek, R.L.; Mueller, S.B.; Hanselman, J.C.; Rosebury, W.S.; Robertson, A.W.; Kindt, E.K.; Homan, R.; Karathanasis, S.K.; Rekhter, M.D. Inhibition of sphingomyelin synthesis reduces atherogenesis in apolipoprotein E-knockout mice. Circulation 2004, 110, 3465-3471.

155. Lan, W.; Zhu, H.; Zhou, Z.; Ye, C.; Liu, M. 1H NMR investigation on interaction between ibuprofen and lipoproteins. Chem. Phys. Lipids 2007, 148, 105-111.

156. Jones, J.W.; Ways, P. Abnormalities of high density lipoproteins in abetalipoproteinemia. J. Clin. Invest. 1967, 46, 1151-1161.

157. Barenholz, Y.; Yechiel, E.; Cohen, R.; Deckelbaum, R.J. Importance of cholesterol-phospholipid interaction in determining dynamics of normal and abetalipoproteinemia red blood cell membrane. Cell. Biophys. 1981, 3, 115-126.

158. Herbert, P.N.; Hyams, J.S.; Bernier, D.N.; Berman, M.M.; Saritelli, A.L.; Lynch, K.M.; Nichols, A.V.; Forte, T.M. Apolipoprotein B-100 deficiency. Intestinal steatosis despite apolipoprotein B-48 synthesis. J. Clin. Invest. 1985, 76, 403-412.

159. Leventhal, A.R.; Chen, W.; Tall, A.R.; Tabas, I. Acid sphingomyelinase-deficient macrophages have defective cholesterol trafficking and efflux. J. Biol. Chem. 2001, 276, 44976-44983. 
160. Dastani, Z.; Ruel, I.L.; Engert, J.C.; Genest, J., Jr.; Marcil, M. Sphingomyelin phosphodiesterase-1 (SMPD1) coding variants do not contribute to low levels of high-density lipoprotein cholesterol. BMC Med. Genet. 2007, 8, 79.

161. Dubois, G.; Mussini, J.M.; Auclair, M.; Battesti, J.; Boutry, J.M.; Kemeny, J.L.; Maziere, J.C.; Turpin, J.C.; Hauw, J.J. Adult sphingomyelinase deficiency: report of 2 patients who initially presented with psychiatric disorders. Neurology 1990, 40, 132-136.

162. Lee, C.Y.; Lesimple, A.; Larsen, A.; Mamer, O.; Genest, J. ESI-MS quantitation of increased sphingomyelin in Niemann-Pick disease type B HDL. J. Lipid Res. 2005, 46, 1213-1228.

163. Lee, C.Y.; Krimbou, L.; Vincent, J.; Bernard, C.; Larramee, P.; Genest, J., Jr.; Marcil, M. Compound heterozygosity at the sphingomyelin phosphodiesterase-1 (SMPD1) gene is associated with low HDL cholesterol. Hum. Genet. 2003, 112, 552-562.

164. Lee, C.Y.; Lesimple, A.; Denis, M.; Vincent, J.; Larsen, A.; Mamer, O.; Krimbou, L.; Genest, J.; Marcil, M. Increased sphingomyelin content impairs HDL biogenesis and maturation in human Niemann-Pick disease type B. J. Lipid Res. 2006, 47, 622-632.

165. Tamasawa, N.; Takayasu, S.; Murakami, H.; Yamashita, M.; Matsuki, K.; Tanabe, J.; Matsui, J.; Satoh, K.; Suda, T. Reduced cellular cholesterol efflux and low plasma high-density lipoprotein cholesterol in a patient with type B Niemann-Pick disease because of a novel SMPD-1 mutation. J. Clin. Lipidol. 2012, 6, 74-80.

166. Yao, J.K.; Herbert, P.N.; Fredrickson, D.S.; Ellefson, R.D.; Heinen, R.J.; Forte, T.; Dyck, P.J. Biochemical studies in a patient with a Tangier syndrome. J. Neuropathol. Exp. Neurol. 1978, $37,138-154$.

167. Pruzanski, W.; Stefanski, E.; de Beer, F.C.; de Beer, M.C.; Ravandi, A.; Kuksis, A. Comparative analysis of lipid composition of normal and acute-phase high density lipoproteins. J. Lipid Res. 2000, 41, 1035-1047.

168. Papathanasiou, A.; Kostara, C.; Cung, M.T.; Seferiadis, K.; Elisaf, M.; Bairaktari, E.; Goudevenos, I.A. Analysis of the composition of plasma lipoproteins in patients with extensive coronary heart disease using 1H NMR spectroscopy. Hellenic J. Cardiol. 2008, 49, 72-78.

169. Bagdade, J.D.; Subbaiah, P.V. Abnormal high-density lipoprotein composition in women with insulin-dependent diabetes. J. Lab. Clin. Med. 1989, 113, 235-240.

170. Bagdade, J.D.; Subbaiah, P.V. Whole-plasma and high-density lipoprotein subfraction surface lipid composition in IDDM men. Diabetes 1989, 38, 1226-1230.

171. Chapkin, R.S.; Haberstroh, B.; Liu, T.; Holub, B.J. Characterization of the individual phospholipids and their fatty acids in serum and high-density lipoprotein of the renal patient on long-term maintenance hemodialysis. J. Lab. Clin. Med. 1983, 101, 726-735.

172. Makinen, V.P.; Tynkkynen, T.; Soininen, P.; Peltola, T.; Kangas, A.J.; Forsblom, C.; Thorn, L.M.; Kaski, K.; Laatikainen, R.; Ala-Korpela, M.; et al. Metabolic diversity of progressive kidney disease in 325 patients with type 1 diabetes (the FinnDiane Study). J. Proteome Res. 2012, 11, 1782-1790.

173. Makinen, V.P.; Tynkkynen, T.; Soininen, P.; Forsblom, C.; Peltola, T.; Kangas, A.J.; Groop, P.H.; Ala-Korpela, M. Sphingomyelin is associated with kidney disease in type 1 diabetes (The FinnDiane Study). Metabolomics 2012, 8, 369-375. 
174. Kuliszkiewicz-Janus, M.; Baczynski, S. Chemotherapy-associated changes in 31P MRS spectra of sera from patients with multiple myeloma. NMR Biomed. 1995, 8, 127-132.

175. Pussinen, P.J.; Jauhiainen, M.; Vilkuna-Rautiainen, T.; Sundvall, J.; Vesanen, M.; Mattila, K.; Palosuo, T.; Alfthan, G.; Asikainen, S. Periodontitis decreases the antiatherogenic potency of high density lipoprotein. J. Lipid Res. 2004, 45, 139-147.

176. Ozerova, I.N.; Perova, N.V.; Shchel'tsyna, N.V.; Mamedov, M.N. Parameters of high-density lipoproteins in patients with arterial hypertension in combination with other components of metabolic syndrome. Bull. Exp. Biol. Med. 2007, 143, 320-322.

177. Francone, O.L.; Subbaiah, P.V.; van Tol, A.; Royer, L.; Haghpassand, M. Abnormal phospholipid composition impairs HDL biogenesis and maturation in mice lacking Abca1. Biochemistry 2003, 42, 8569-8578.

178. Jeong, T.; Schissel, S.L.; Tabas, I.; Pownall, H.J.; Tall, A.R.; Jiang, X. Increased sphingomyelin content of plasma lipoproteins in apolipoprotein E knockout mice reflects combined production and catabolic defects and enhances reactivity with mammalian sphingomyelinase. J. Clin. Invest. 1998, 101, 905-912.

179. Dong, J.; Liu, J.; Lou, B.; Li, Z.; Ye, X.; Wu, M.; Jiang, X.C. Adenovirus-mediated overexpression of sphingomyelin synthases 1 and 2 increases the atherogenic potential in mice. J. Lipid Res. 2006, 47, 1307-1314.

180. Wang, X.; Dong, J.; Zhao, Y.; Li, Y.; Wu, M. Adenovirus-mediated sphingomyelin synthase 2 increases atherosclerotic lesions in ApoE KO mice. Lipids Health Dis. 2011, 10, 7.

181. Siggins, S.; Bykov, I.; Hermansson, M.; Somerharju, P.; Lindros, K.; Miettinen, T.A.; Jauhiainen, M.; Olkkonen, V.M.; Ehnholm, C. Altered hepatic lipid status and apolipoprotein A-I metabolism in mice lacking phospholipid transfer protein. Atherosclerosis 2007, 190, 114-123.

182. Li, Z.; Li, Y.; Chakraborty, M.; Fan, Y.; Bui, H.H.; Peake, D.A.; Kuo, M.S.; Xiao, X.; Cao, G.; Jiang, X.C. Liver-specific deficiency of serine palmitoyltransferase subunit 2 decreases plasma sphingomyelin and increases apolipoprotein E levels. J. Biol. Chem. 2009, 284, 27010-27019.

(C) 2013 by the authors; licensee MDPI, Basel, Switzerland. This article is an open access article distributed under the terms and conditions of the Creative Commons Attribution license (http://creativecommons.org/licenses/by/3.0/). 